\title{
Performance of the LHC Final Design Full Scale Superconducting Dipole Prototypes
}

\author{
L. Bottura, P. Pugnat, A. Siemko, J. Vlogaert, and C. Wyss
}

\begin{abstract}
Within the LHC magnet program, a series of six, final design, full-scale superconducting dipole prototypes are presently being built in industry and tested at CERN. The main features of these magnets are: two-in-one structure, $56 \mathrm{~mm}$ aperture, six-block two layer coils wound from $15.1 \mathrm{~mm}$ wide graded NbTi cables, and all-polyimide insulation. This paper reviews the main test results of magnets tested to day at $4.2 \mathrm{~K}$ and $1.8 \mathrm{~K}$. The results of the quench training, conductor performance, magnet protection, sensitivity to ramp rate and field quality are presented and discussed in terms of the design parameters and the aims of the full scale dipole prototype program.
\end{abstract}

Index Terms-Large Hadron Collider, Superconducting dipole magnets, Quench Training, Magnet field quality.

\section{INTRODUCTION}

$\mathrm{T}$ he Large Hadron Collider (LHC) at CERN will consist of two synchrotron rings installed in the existing $27 \mathrm{~km}$ LEP tunnel [1]. Two superconducting magnetic channels will guide the counter-rotating proton beams at the unprecedented energy of $7 \mathrm{TeV}$ each. To bend $7 \mathrm{TeV}$ protons around the ring, the LHC dipoles must be able to produce a field of $8.33 \mathrm{~T}$. The dipoles, like all other main ring magnets will be operated at $1.9 \mathrm{~K}$. Their coils are housed in a common forceretaining laminated collar structure, laminated yoke and cryostat. This unique two-in-one configuration not only saves space but also gives a cost saving over separate rings.

The experimental program on the LHC $10 \mathrm{~m}$ long, two-inone, main dipoles started on the turn of 1989-1990. Since then 7 magnets of the $1^{\text {st }}$ generation and 5 of the $2^{\text {nd }}$ generation have been built in industry and tested at CERN. The design and main test results of these magnets were described in several earlier publications [2], [3].

In summer $1998 \mathrm{CERN}$ has lunched fabrication of six $3^{\text {rd }}$ generation, final design, full-scale dipole prototype collared coils in industry. These collared coils are subsequently assembled into cryo-dipoles at the CERN Magnet Assembly Facility and tested at the CERN Magnet Test Plant before the assembly of the first ninety pre-series magnets commences.

In this paper we review the main test results of magnets tested to day at $4.2 \mathrm{~K}$ and $1.8 \mathrm{~K}$. We discuss results of quench training, conductor performance, magnet protection, sensitivity to ramp rate and field quality in terms of the design

Manuscript received September 18, 2000.

Authors are with the European Laboratory for Nuclear Research, CH-1211 Geneva 23, Switzerland (telephone: +41-22-7676635, e-mail: Andrzej.Siemko@cern.ch). parameters and the aims of the full scale dipole prototype program.

\section{MAGNET DESIGN AND FABRICATION VARIANTS}

The design of the $3^{\text {rd }}$ and final generation of the LHC full scale superconducting dipole prototypes has been described in details in earlier publications [4]-[6]. The construction of these magnets is the result of close collaboration between CERN and European Industry. Here we recall only main design features and fabrication variants in view of the discussion of the test results.

\section{A. Main Design Features}

The $3^{\text {rd }}$ generation coils are wound with two different, $15.1 \mathrm{~mm}$ wide, graded NbTi Rutherford cables. The cable for the inner layer consists of 28 strands of $1.065 \mathrm{~mm}$ diameter, while that for the outer layer consists of 36 strands of $0.825 \mathrm{~mm}$ diameter. Contrary to the "5-block" coil of the $2^{\text {nd }}$ generation, in the $3^{\text {rd }}$ generation the conductors of each quadrant are distributed in six blocks (see Fig. 1). In terms of magnetic design this is the most important difference between the $2^{\text {nd }}$ and the $3^{\text {rd }}$ generation dipoles. The cable insulation is all polyimide and composed typically of two layers of $25 \mu \mathrm{m}$ thick tapes each overlapped by $50 \%$, and a third $70 \mu \mathrm{m}$ thick adhesive coated layer, spaced by $2 \mathrm{~mm}$ to provide channels for helium penetration inside the coils.

\section{B. Manufacturing Features and Assembly Variants}

All two-in-one magnets have a single race track type collar, embracing the coils of the two dipole channels. Before the collaring process the thickness of the correcting shims is calculated on the basis of the required prestress, the actual size of the coils and the Young's modulus measurements. The target value of the residual prestress is 25 to $35 \mathrm{MPa}$ at cold condition, on both the inner and the outer layer. The main manufacturing variants, specific for each company or introduced for evaluation in view of the series production are listed in Table I. For the purpose of the test results discussion similar data of the $2^{\text {nd }}$ generation dipoles are also included.
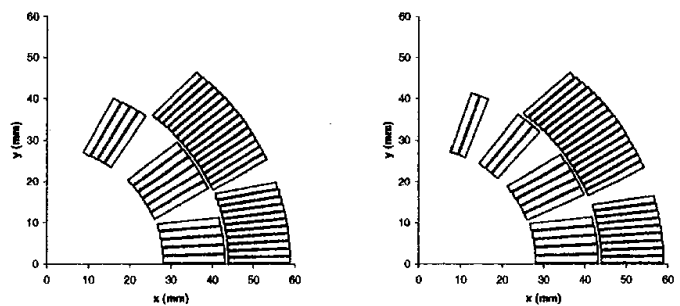

Fig. 1. Nominal geometry of one quadrant of the 5-block and 6-block dipole coils. 
TABLE I

MAIN DESIGN AND ASSEMBLY VARIANTS

\begin{tabular}{|c|c|c|c|c|c|}
\hline \multirow{6}{*}{$\begin{array}{l}\text { 몽 } \\
\text { 营 } \\
\text { 总 } \\
\text { 总 }\end{array}$} & $\begin{array}{l}\text { Magnet } \\
\text { Name }\end{array}$ & $\begin{array}{l}\text { Magnetic } \\
\text { Length }\end{array}$ & $\begin{array}{c}\text { Collar } \\
\text { Material }\end{array}$ & $\begin{array}{l}\text { Collaring } \\
\text { Mandrel }\end{array}$ & $\begin{array}{l}\text { Collar } \\
\text { Packs }\end{array}$ \\
\hline & MBL_1N1 & $9.3 \mathrm{~m}$ & Al & Expandable & 32 pairs \\
\hline & MBL1N2 & $9.3 \mathrm{~m}$ & $\mathrm{Al}$ & Expandable & 32 pairs \\
\hline & MBLIJA1 & $9.3 \mathrm{~m}$ & $\mathrm{Al}$ & None & 1 pair \\
\hline & MBL1JA2 & $9.3 \mathrm{~m}$ & $\mathrm{Al}$ & None & 1 pair \\
\hline & MBPIAl & $14.3 \mathrm{~m}$ & $\mathrm{Al}$ & Rigid & 32 pairs \\
\hline \multirow{6}{*}{ 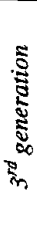 } & MBP2N1 & $14.3 \mathrm{~m}$ & Al & Expandable & 32 pairs \\
\hline & $\mathrm{MBP} 2 \mathrm{~N} 2$ & $14.3 \mathrm{~m}$ & St. St. & Expandable & 32 pairs \\
\hline & $\mathrm{MBP} 2 \mathrm{Ol}$ & $14.3 \mathrm{~m}$ & St. St. & None & 1 pair \\
\hline & $\mathrm{MBP} 2 \mathrm{O} 2$ & $14.3 \mathrm{~m}$ & St. St. & None & 1 pair \\
\hline & MBP2A1 & $14.3 \mathrm{~m}$ & St. St. & Rigid & 32 pairs \\
\hline & MBP2A2 & $14.3 \mathrm{~m}$ & St. St. & Rigid & 32 pairs \\
\hline
\end{tabular}

\section{POWER TESTS AND QUENCH PERFORMANCE}

For the cold tests, fully equipped $15 \mathrm{~m}$ long dipole units were attached to the one of newly constructed test stations at CERN. For testing, the beam screens are not installed in the magnet apertures to be able to insert the so-called "anticryostats" allowing the positioning of the warm measuring shafts, both for quench location and magnetic field quality measurements [7].

\section{A. Quench Training}

The power test campaigns of the dipoles are typically carried out in several runs separated by thermal cycles from $1.8 \mathrm{~K}$ to room temperature and back to $1.8 \mathrm{~K}$. For the standard training test, the quench current was reached with a nominal linear ramp rate of $10 \mathrm{~A} / \mathrm{s}$. Fig. 2 shows the quench performance recorded during the first runs for all magnets tested to day. All magnets after some training reached the nominal field of $8.33 \mathrm{~T}$. Regarding the first quench level and the number of training quenches needed to exceed the nominal field, the $3^{\text {rd }}$ generation dipole magnets have shown in average better training behaviour compared to the $2^{\text {nd }}$ generation ones (cf. Table II). This improvement is however lower than could be anticipated from the single aperture short model program [8] essentially because in the double-aperture design the coils ends are exposed to higher fields. Comparing further the magnets of the two generations it follows that the performance enhancement is relative to the collared coil manufacturer. So far, independently of the coil structural design, the general training performance seems to be predominantly influenced by the particular assembly details chosen by industry in the course of the prototype work. The same conclusion applies to the so-called spikes, the quench precursors resulting from conductor micro-motions. This subject will be presented in a separate paper [9].

The $3^{\text {nd }}$ generation prototypes tested so far show the importance of an optimised design and manufacture of the coil ends, where most of the training quenches occurred. This matter is receiving full attention and the improving training behaviour shown in Fig. 2 may be explained by positive actions (appropriate prestress, end spacer shape) taken in the course of the prototype work. The instabilities of the training curves shown in Fig. 2 are attributed to a de-training effect. This effect has a thermo-mechanical origin induced by the coexistence of a mechanically weak region and the temperature rise provoked by the energy deposited during the previous quench. The coil ends of the $3^{\text {rd }}$ generation magnets exhibit more pronounced sensitivity to the de-training effect, as observed as well on double-aperture short models, which occurs in the pole turn of the outer layer. The mechanical weakness of this region is reflected in the location of training quenches, summarized in Fig. 3 where the difference between $2^{\text {nd }}$ and $3^{\text {rd }}$ generation magnets is clearly visible.

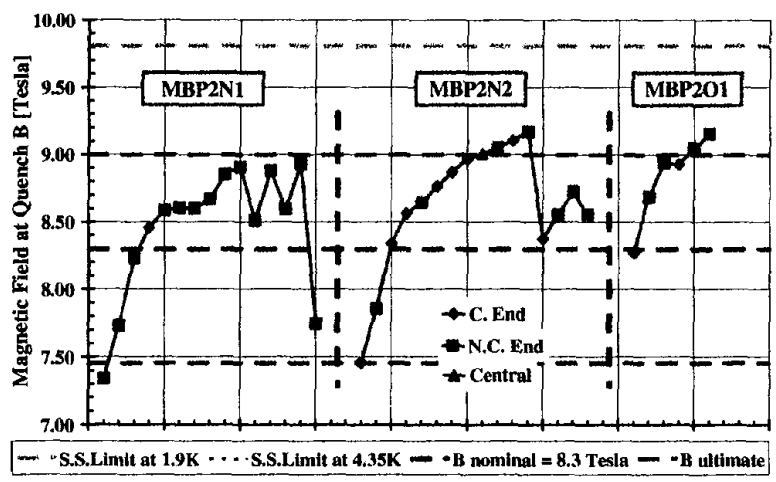

Fig. 2. Training curves recorded during the first runs for all $3^{\text {rd }}$ generation prototype dipoles tested to day. Spot shapes denotes the quench positions.

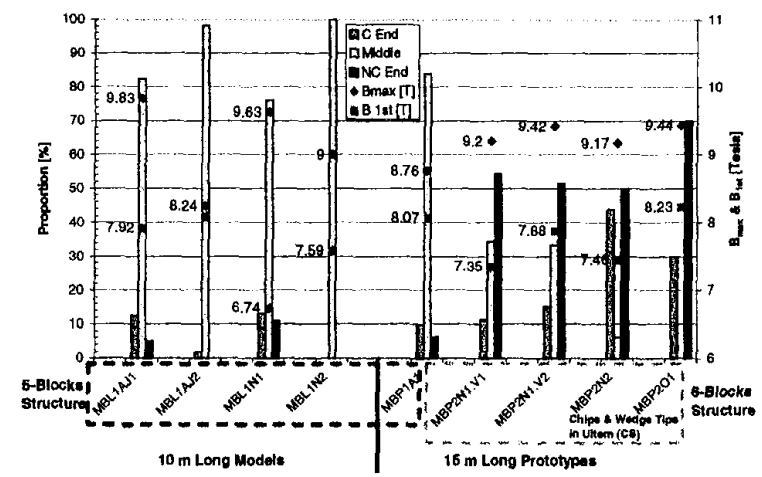

Fig. 3. Distribution of training quench locations for the $2^{\text {nd }}$ and $3^{\text {rd }}$ generation LHC main dipole prototypes.

TABLE II

SUMMARY OF TRAINING QUENCH PERFORMANCE

\begin{tabular}{|c|c|c|c|c|c|}
\hline & $\begin{array}{l}\text { Magnet } \\
\text { Name }\end{array}$ & $\begin{array}{c}\text { First } \\
\text { quench } \\
\text { [T] }\end{array}$ & $\begin{array}{c}\text { No of } \\
\text { q. to } \\
8.33 \mathrm{~T}\end{array}$ & $\begin{array}{l}\text { No of } \\
\text { q. to } \\
9 \mathrm{~T}\end{array}$ & $\begin{array}{c}1^{\text {st }} \mathrm{q} \text {. after th. cycle } \\
{[\mathrm{T}]}\end{array}$ \\
\hline \multirow{5}{*}{ 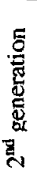 } & MBLINl & 6.74 & 8 & 11 & 8.75 \\
\hline & MBL1N2 & 7.59 & 16 & $>26$ & 7.89 \\
\hline & MBL 1 JA1 & 7.92 & 1 & 8 & 9.06 \\
\hline & MBL1JA2 & 8.16 & N/A & N/A & N/A \\
\hline & MBP1Al & 8.07 & 6 & $>20$ & 8.03 \\
\hline \multirow{6}{*}{ 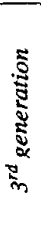 } & MBP2N1 & 7.35 & 3 & $>15$ & 8.39 \\
\hline & MBP2N2 & 7.46 & 2 & 8 & - \\
\hline & MBP2O1 & 8.23 & 1 & 5 & 8.76 \\
\hline & $\mathrm{MBP} 2 \mathrm{O} 2$ &.$^{\mathrm{a}}$ & $\sim^{a}$ & $-^{\mathbf{a}}$ & $-{ }^{\mathfrak{a}}$ \\
\hline & MBP2A1 & $-a^{a}$ & $-^{\mathrm{a}}$ & $-{ }^{\mathrm{a}}$ & ${ }^{\mathrm{a}}$ \\
\hline & MBP2A2 & 7.25 & $-{ }^{\mathrm{a}}$ & $-^{a}$ & $\mathrm{a}^{\mathrm{a}}$ \\
\hline
\end{tabular}

${ }^{\mathrm{a}}$ Magnet not yet tested or test in due course. 


\section{B. Magnet Protection}

All prototype dipole magnets are protected against quench induced damages by means of quench heaters activated by the quench detection electronics. For certain tests like quench training an energy extraction to an external dump resistor is used. Usually $10 \%$ to $20 \%$ of the total stored energy is extracted. To ensure safe operation of this type of magnets when connected in series, quenches without energy extraction at various fields through excitation have been performed. The aims of these tests were to investigate the efficiency of quench heaters as well as to validate the new protection scheme for the LHC dipoles [9]. The tests demonstrated that the proposed quench heater scheme is fully redundant and that neither the highest hot-spot temperatures reached during quenches at high currents nor the resulting voltages to the ground do not exceed the design values [10], [11].

\section{Quench Sensitivity to the Ramp Rate}

The sensitivity to ramp rate of the $3^{\text {rd }}$ generation dipoles is in general very low and not much different from magnet to magnet. Results show significant improvement in this respect as compared to the $2^{\text {nd }}$ generation magnets, thanks to the strand coating ( $\mathrm{SnAg}_{5 \% \text { wt. }}$ ) oxidation process developed at CERN for the $3^{\text {rd }}$ generation magnets. For the previous generations certain magnets used to quench when going down from nominal field with a ramp rate close to $120 \mathrm{~A} / \mathrm{s}$, required to discharge in time a series of magnets when one of them quenches and is short-circuited by a by-pass diode. Present magnets exhibit a very comfortable margin in this respect.

\section{FIELD QUALITY}

The magnetic field of the $10 \mathrm{~m}$ long dipole prototypes of the $2^{\text {nd }}$ generation was measured scanning the bore length with a $750 \mathrm{~mm}$ long rotating coil [12]. All $15 \mathrm{~m}$ long dipoles prototypes were measured with a long coil system [7]. Measurements of the field were performed at several current levels, including injection $(0.54 \mathrm{~T})$ and flat-top $(8.3 \mathrm{~T})$ conditions. In Fig. 4 we compare the dipole transfer function in the straight part of all 10-m and 15-m long magnets. We can clearly distinguish the two coil designs. The dipoles built with a 5-block coil have a slightly higher transfer function $(0.74 \mathrm{~T} / \mathrm{kA})$ compared to the dipoles built with 6-block coil $(0.71 \mathrm{~T} / \mathrm{kA})$. Magnets of the $2^{\text {nd }}$ generation feature however

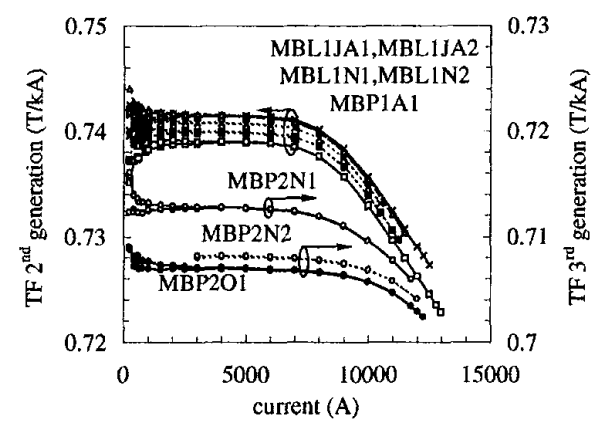

Fig. 4. Dipole transfer function, measured along the magnet loadline in the first aperture of $2^{\text {nd }}$ and $3^{\text {td }}$ generation magnets. Results in the second aperture generally agree to better than few $10^{-4}$ with those plotted. much higher saturation at flat-top field, thus making the difference in the nominal operating current only approximately $2 \%$. The transfer function of the MBP2N1 dipole is higher than the other $3^{\text {rd }}$ generation magnets because of an adapted ferromagnetic yoke with an hybrid geometry due to component availability. The results from this dipole are therefore not directly representative of the pre-series design.

The main reason for the change in coil geometry from 5-block to 6-block was to gain flexibility in the adjustment of geometric harmonics. In fact it was found during design iterations on the $2^{\text {nd }}$ generation dipoles that the tuning range for the 5-block coil was exhausted. The 6-block geometry offers additional degrees of freedom for adjusting allowed multipoles, and in particular to offset the coil contribution to normal sextupole and decapole to compensate partially the effect of persistent currents in the superconducting filaments at injection [6]. The gain obtained in moving to the 6-block geometry is evident in Fig. 5, where we report a summary of the measured harmonics at injection and at flat-top field. Normal and skew field harmonics, $b_{n}$ and $a_{n}$ respectively, are normalised to the dipole field, scaled by a factor $10^{4}$ and expressed at a reference radius of $17 \mathrm{~mm}$. The harmonics plotted are averaged over the magnets of the same family. The large negative sextupole $b_{3}$ and positive decapole $b_{5}$ at injection that are characteristic of the magnets of the $2^{\text {nd }}$ generation have been successfully compensated in the magnets of the $3^{\text {rd }}$ generation.

The persistent current contribution to $b_{3}$ and $b_{5}$ is essentially the same irrespective of the coil geometry, and the optimisation has not affected significantly most harmonics of higher order. The larger freedom inherent in the 6-block design also makes it possible to fine-tune the final geometry
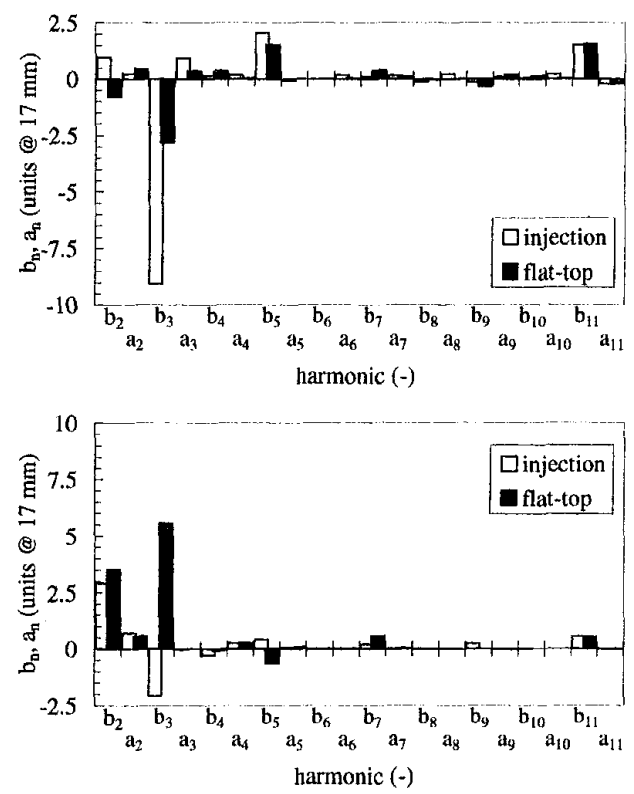

Fig. 5. Summary of harmonics measured at injection and flat-top field in the $2^{\text {nd }}$ and $3^{\text {rd }}$ generation dipole prototypes. The harmonics reported are average values over the magnets of the same family. 


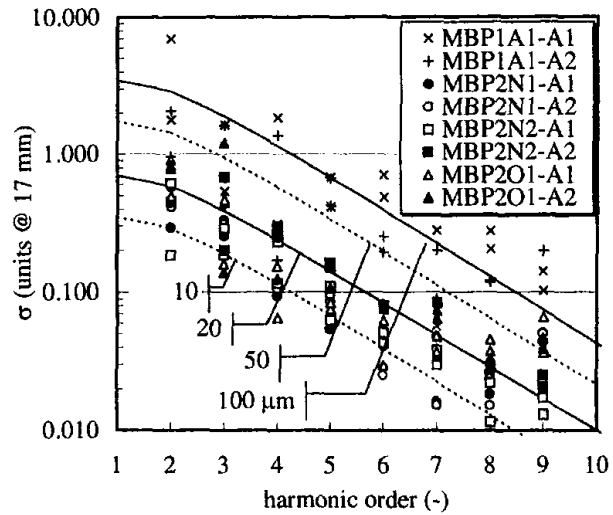

Fig. 6. Standard deviation of harmonics measured along the magnet apertures for all $15-\mathrm{m}$ long prototypes.

of pre-series dipoles to achieve optimal field quality for machine operation.

A key parameter for field quality considerations is the spread of harmonics among magnets. Lacking a statistically relevant number of identical magnets, it is not yet possible to establish a reliable measurement of the random errors. Using the approach of [13] however, the expected random variation of conductor positions can be estimated by evaluating the standard deviation of the harmonics along the magnet aperture. We have performed this analysis on the field components of the four $15-\mathrm{m}$ long dipoles tested so far: MBP1A1, MBP2N1, MBP2N2 and MBP2O1. The results are shown in Fig. 6. We note firstly that the standard deviation obtained for the 5-block MBP1A1 is much larger than for the 6-block magnets. A comparison of these data with the results obtained on the $10-\mathrm{m}$ prototypes seem to indicate that this a feature associated with the 5-block geometry. Furthermore we notice that all 6-block magnets have comparable standard deviations, irrespective of the collar material (i.e. Al for MBP2N1 and SS for MBP2N2, MBP2O1). This analysis demonstrates that, as foreseen in the calculation [6], the 6-block geometry is superior from the point of view of manufacturing tolerances. Using the scaling law derived in [13] it is possible to estimate the expected standard deviation for a given random displacement of the conductors. Comparing the measured standard deviation to the values expected from the scaling law we see that the random accuracy of conductor placement is in the range of 10 to $20 \mu \mathrm{m}$, coherent with the present assumption on the manufacturing accuracy for series production.

\section{V.CONCLUSIONS}

An extensive test and analysis program is being pursued for the LHC main dipole prototype magnets of the final design. To this point, all tested magnets passed nominal field. Results show that the $3^{\text {rd }}$ generation dipole magnets display on average better training behaviour and a significant improvement of field quality. We note however that the training performance carries the signature of the manufacturers, in the $3^{\text {rd }}$ generation magnets also because of the different assembly techniques knowingly applied in the coil ends in the course of the prototype work. So far, independent of the coil structural design, the general training performance seems to be predominantly affected by the particular assembly details, different at each company.

In view of the LHC main dipole series production, the acquired experience points out the importance of a standardised and as homogeneous as possible manufacturing processes, controlled by strict assembly and quality assurance procedures and finally by thorough testing prior to installation.

\section{ACKNOWLEDGEMENT}

The authors wish to thank $\mathrm{L}$. Evans and Ph. Lebrun for their constant support and are very grateful to the teams in Industry and at CERN involved in the construction and testing of the LHC main dipole magnets.

\section{REFERENCES}

[1] The LHC Study Group, "The Large Hadron Collider Conceptual Design", CERN, CERN/AC/95-05(LHC), 20 October, 1995.

[2] J. Billan et al., "Manufacturing features and performances of long models and first prototype for the LHC project", Proc. of $6^{\text {th }}$ European Part. Acc. Conf., Stockholm, pp. 2041-2043, 1998.

[3] J. Billan et al., "Test Results on the Long Models and Full Scale Prototype of the Second Generation LHC Arc Dipoles", IEEE Trans. Appl. Sup., 9(2), pp. 1039-1044, 1999.

[4] C. Wyss, "LHC arc dipole status report", Proc. of 1999 Part. Acc. Conf., New York, pp. 149-153, 1999.

[5] K. Artoos et al.," Design, manufacturing status, first results of the LHC main dipole final prototypes and steps towards series manufacture", IEEE Trans. on Appl. Superconductivity, 10(1), pp. 98-102, 2000.

[6] S. Russenschuck, "Comparative study of different coils for the L.HC main dipoles", in Roxie: Routine for the optimization of magnet $X$-sections, inverse field calculation and coil end design, S. Russenschuck ed., CERN 99-01, 12 April, 1999.

[7] J. Billan et al., "Twin rotating coils for cold magnetic measurements of $15 \mathrm{~m}$ long LHC dipoles", IEEE Trans. on Appl. Sup., vol. 10, No 1 , pp. 1422-1426, March 2000

[8] N. Andreev et al., "Performance of five and six block coil geometries in short superconducting dipole models for the LHC", Proc. of 1999 Part. Acc. Conf., New York, pp. 154-156, 1999.

[9] P. Pugnat, B. Khomenko, A. Rijllart, S. Sanfilippo, and A. Siemko, "Statistical diagnosis method of conductor motions in superconducting magnets to predict their quench performance", paper presented at Appl. Sup. Conf., Virginia Beach, September 2000.

[10] F. Rodriguez-Mateos, R. Schmidt, A. Siemko, F. Sonneman, "Quench process and Protection of LHC Dipole Magnets", CERN LHC Project Note 184, July $1^{\text {st }}, 1999$.

[11] F. Rodriguez-Mateos, P. Pugnat, S. Sanfilippo, R. Schmidt, A. Siemko, F. Sonnemann, "Quench heater experiments on the LHC main superconducting magnets", Proc. of $7^{\text {th }}$ European Part. Acc. Conf., Vienna, pp. 2154-2156, 2000.

[12] J. Billan et al., "Design and test of the Benches for the Magnetic Measurement of the LHC Dipoles", IEEE Trans. Mag., 30, pp. 26582661, 1994.

[13] W. Scandale, E. Todesco, R. Wolf, "Random Errors Induced by the Superconducting Windings in the LHC Dipoles", IEEE Trans. Appl. Sup., 10(1), pp. 93-97, 2000. 